\title{
NATIONAL EXUBERANCE: A NOTE ON THE MELBOURNE CUP EFFECT IN AUSTRALIAN STOCK RETURNS
}

by

\begin{abstract}
ANDREW C. WORTHINGTON*
This note examines the presence of a Melbourne Cup effect in Australian daily stock returns over the forty-five years from 3 January 1961 to 30 December 2005. First run in 1861, the Melbourne Cup is Australia's premier horse race and one of the world's leading handicaps. Parametric tests of differences in means and a regression-based approach are used to test for the effect alongside a conventional day-of-the-week (Tuesday) and month-of-the year (November) effects. The results indicate that the mean Melbourne Cup Day return of 0.1916 is significantly higher than the mean return for other Tuesdays in November (0.2345), Tuesdays in other months of the year (-0.0352), and Monday, Wednesday, Thursday, and Friday returns throughout the year (0.0516). This suggests the exuberance associated with Australia's unofficial national day is translated into irrationally positive market behaviour.
\end{abstract}

Keywords: Calendar effects, Market anomalies, Day-of-the-week effect, Monthof-the-year effect

JEL code: G14; C22

The Melbourne Cup is the Australasian National Day. It would be difficult to overstate its importance. It overshadows all other holidays and specialised days of whatever sort in that congeries of colonies. Overshadows them? I might almost say it blots them out. Each of them gets attention, but not everybody's; each of them evokes interest, but not everybody's; each of them rouses enthusiasm, but not everybody's; in each case a part of the attention, interest, and enthusiasm is a matter of habit and custom, and another part of it is official and perfunctory. Cup Day, and Cup Day only, commands an attention, an interest, and an enthusiasm which are universal-and spontaneous, not perfunctory. Cup Day is supreme; it has no rival. I can call to mind no specialised annual day, in any country, which can be named by that large name-Supreme. I can call to mind no specialised annual day, in any country, whose approach fires the whole land with a conflagration of conversation and preparation and anticipation and jubilation. No day save this one; but this one does it.

Mark Twain, Following the Equator (1897)

School of Accounting and Finance, University of Wollongong. The author would like to thank the joint editor, Russell Smyth, and an anonymous referee for their helpful comments on an earlier version of this note. 


\section{Introduction}

The Melbourne Cup is Australia's premier horse race. Billed as the race that stops a nation, it has been held on the first Tuesday in November since 1861, and is now regarded as one of the world's leading handicap horse races. From a humble beginning when just four thousand spectators witnessed seventeen horses in fading light race for a gold watch and £170, with the winner, Archer, apocryphally walking the eight hundred kilometres from New South Wales to take part, the 2005 Melbourne Cup was held before a crowd of 106,479, with third-time winner, Makybe Diva, taking her share of $\$ 5.1$ million in prize money. Beyond the track, 2.6 million more Australians watched the race on television, wagered a record $\$ 144$ million through the nation's totalisor agencies, bet informally in the time-honoured tradition of the office sweep, or indulged at one of the many champagne lunches and race meetings that take place in every state and territory and beyond (estimates suggest the global audience exceeds 1.3 billion people in 161 countries).

Oddly enough, Cup Day is only gazetted as a public holiday in Melbourne. Elsewhere, though the nation stops whatever it's doing at three o'clock to listen to the race call, watch the race on television, and place their bets, the stock market opens and closes as usual. This raises the tantalising prospect of whether the enthusiasm, anticipation and celebration allied with the Melbourne Cup is transferred to stock trading activity. Indeed, does the willingness to bet on the Cup, with more than $80 \%$ of Australians making a wager of some form, reflect a tendency, albeit it transitory, to take a punt on pursuits beyond the equine. Or does the nationwide exuberance, where everyone seems to back the winner and the favourite always wins, become a general feeling of hopeful expectation and goodwill for all activities, including investments, which take place on this one day of the year? This effect is undocumented in the Australian literature.

But such a hypothesis is not out of place with better-known market anomalies concerning security returns, including: a 'weekend effect', where stocks exhibit lower returns between Friday and Monday closing (Agrawal and Ikenberry, 1994; Wang and Erickson, 1997; Zainudin and Coutts, 1997); a 'day-of-the-week effect', where returns on some trading days are higher than others (Chang et al., 1993; Kamara, 1997; Chang et al., 1998); a 'January effect', where returns are much higher than any other month (Haugen and Jorion, 1996; Tonchev and Kim, 2004; Rosenberg, 2004); a 'holiday effect', where returns are higher on trading days prior to public holidays (Kim and Park, 1994; Chan et al., 1996; Brockman and Michayluk, 1998; Arumugum, 1999; Vergin and McGinnis, 1999; Chong et al., 2005; McGuiness, 2005); and a 'turn-of-the month effect', where returns are higher on the last trading day (Cadsby and Ratner, 1992; Tonchev and Kim, 2004).

Nor is it inconsistent, though in an opposing manner, with the 'Friday-the-thirteenth (or superstition) effect', where returns are lower than other Fridays (Chamberlain et al., 1991; Agrawal and Tandon, 1994). But just as the 'Friday-the-thirteenth effect' lies counter to the rational behaviour that underlies most finance research, so too does the notion that the Melbourne Cup contributes to irrationally positive market expectations. It is therefore well-placed in the emergent behavioural finance literature (see Fama [1998], Barberis and Thaler [2003], Shiller [2003], Brav et al. [2004], and van der Sar [2004]). It also joins a burgeoning literature on the effect of sports events on stockmarket activity [see, for instance, Boyle and Walter (2003) and Edmans et al. (2007)] 
The purpose of this paper is to add to this intriguing body of work the results of an analysis of the Melbourne Cup and its impact on the Australian equity market. To my knowledge, this is the first work of its kind in Australia or elsewhere and joins Narayan and Smyth $(2003,2004)$ as the only other works known to me on the economics of the Melbourne Cup. The paper itself is divided into three main areas. Section 2 explains the empirical methodology and data collection employed in the analysis. Section 3 gives my empirical findings and their analysis. The paper ends with a brief conclusion in Section 4.

\section{Research Method and Data}

The data employed in the study are closing prices from the Australian Stock Exchange (ASX) over the period 3 January 1961 to 30 December 2005 encompassing 11,327 trading days. The capitalisation-weighted All Ordinaries Price Index is used. The index includes the top ASX-listed stocks by capitalisation, covering about $92 \%$ of domestic companies by market value. To be included in the index stocks must have an aggregate market value of at least $0.02 \%$ of all domestic equities, and maintain an average turnover in excess of $0.5 \%$ of quoted shares each month. The long-term index includes base recalculations by Global Financial Data (2006).

A series of daily returns are calculated, of which four categories are identified. These are: (i) a daily return calculated from Monday, Wednesday, Thursday, and Friday closing prices; (ii) a daily return for Tuesdays in the months other than November; (iii) a daily return for Tuesdays in November other than Melbourne Cup Tuesday; and (iv) a daily return for all Melbourne Cup Tuesdays ${ }^{1}$

The specification follows evidence by Jaffe and Westerfield (1985), Finn et al. (1991), Easton and Faff (1994), Agrawal and Tandon (1994), and Davidson and Faff (1999) of a significantly negative 'Tuesday effect' in Australian stock returns, with Jaffe and Westerfield (1985) and Lin and Lim (2001) proposing a linkage between Tuesdays in the Asia-Pacific and the (negative) Monday effect in the US. The basic hypothesis is that the Melbourne Cup positively influences market returns on the first Tuesday in November each year. Further, since this 'Melbourne Cup effect' exists in parallel to the Tuesday day-of-the-week effect in Australia returns for other Tuesdays will be lower than Melbourne Cup Tuesday. Finally, since 'day-of-the-week effects' are known to vary alongside with 'month-of-the-year effects', the returns for Tuesdays in November, including Melbourne Cup Tuesday, may differ from Tuesdays in other months.

Two approaches are used to test these hypotheses. The first involves a descriptive analysis of the mean returns and tests of equality of means using parametric analysis. As a rule, the mean return for Melbourne Cup Tuesday is expected to be positive. The mean return for Tuesdays outside Melbourne Cup Tuesday is expected to be negative; the mean returns for other November Tuesdays may be higher or lower than Tuesdays in other months, though still negative. The second is a regression-based approach, where 11,327 daily returns are regressed against variables indicating the Melbourne Cup and related day-of-the-week effects:

Throughout the sample, the Melbourne Cup was held on the first Tuesday in November. When the Cup was first run in 1861 it was held on a Thursday, and this continued until 1874 apart from one Friday in 1863. From 1875 it was run on the first Tuesday in November. Exceptions were 1882, when it was run on the last Tuesday in October; 1916, when rain delayed the race until the following Saturday; and 1942-1944, when racing was restricted to Saturdays during WWII. 


$$
R_{t}=\beta_{0}+\beta_{1} T_{1 t}+\beta_{2} T_{2 t}+\beta_{3} T_{3 t}+\varepsilon_{t}
$$

where $R_{t}$ is the daily Monday to Friday market return at time $t ; T_{1}$ is a dummy variable that equals one on a Melbourne Cup Tuesday and zero otherwise; $T_{2}$ is a dummy variable that equals one on Tuesdays in November other than Melbourne Cup Tuesday and zero otherwise; $T_{3}$ is a dummy variable that equals one for all other Tuesdays and zero otherwise; $\beta_{i}$ are coefficients to be estimated and $\varepsilon$ is the error term. A further regression is estimated using the sub-sample of 2,307 Tuesday returns:

$$
R_{T t}=\beta_{0}+\beta_{1} T_{1 t}+\beta_{2} T_{2 t}+\varepsilon_{t}
$$

where $R_{\mathrm{T} t}$ is the Tuesday return at time $t$ and all other variables are as previously defined. Following the hypotheses presented, the sign on the coefficient for $T_{1}$ is expected to be positive, and the signs on $T_{2}$ and $T_{3}$ are expected to be negative. The hypothesised magnitude of $T_{2}$ may be larger or smaller than $T_{3}$. The null hypothesis tested is:

$$
H_{0}: \beta_{0}=\beta_{1}=\beta_{2}=\beta_{3}
$$

as compared with the alternative that not all $\beta$ sare equal. If the null hypothesis is rejected, then the stock returns exhibit some form of seasonality. An Augmented Dickey-Fuller test (statistic $=-55.4424 ; p$-value $=0.0000$ ) and a Phillips-Peron test (with allowance for autocorrelation) (statistic $=-93.1849$; $p$-value $=0.0000$ ) eliminate the null hypothesises of a unit root and we conclude that the return series is stationary and suitable for regression-based analysis.

\section{Empirical Findings}

The market index and returns are plotted in Figure 1. Table 2 presents the summary of descriptive statistics for the daily returns. These are categorised according to the Melbourne Cup and 'day-of-the-week effects' hypothesised: namely: (i) Melbourne Cup Tuesdays; (ii) November Tuesdays other than Melbourne Cup Tuesday; (iii) Tuesdays in months outside November; and (iv) all other days. As shown, mean returns are highest on Melbourne Cup Tuesdays (0.1916) and lowest on the remaining November Tuesdays $(-0.2345)$. The volatility of returns (as measured by their standard deviation) is highest on other days (0.8188) and lowest on Melbourne Cup Tuesdays (0.5574). By and large, the distributional properties of all four series appear non-normal. Given that the sampling distribution of skewness is normal, with mean 0 and standard deviation of $\sqrt{6 / T}$ (where $T$ is the sample size), then returns on Melbourne Cup Tuesdays and November Tuesdays (Other Tuesdays and other days) are significantly positively (negatively) skewed, indicating the greater likelihood of observations lying above (below) the mean. The kurtosis or degree of excess across all returns is also large, indicating leptokurtic distributions with many extreme observations. Given that the sampling distribution of kurtosis is normal with mean 0 and a standard deviation of $\sqrt{24 / T}$ (where $T$ is again the sample size), then all estimates are once again statistically significant at any conventional level. Finally, the Jarque-Bera statistics reject the null hypotheses of normality at the 0.01 level for all series. 
FIGURE 1

DAILY ALL ORDINARIES INDEX AND RETURNS (TUESDAY 3 JANUARY 1961 TO FRIDAY 30 DECEMBER 2005)

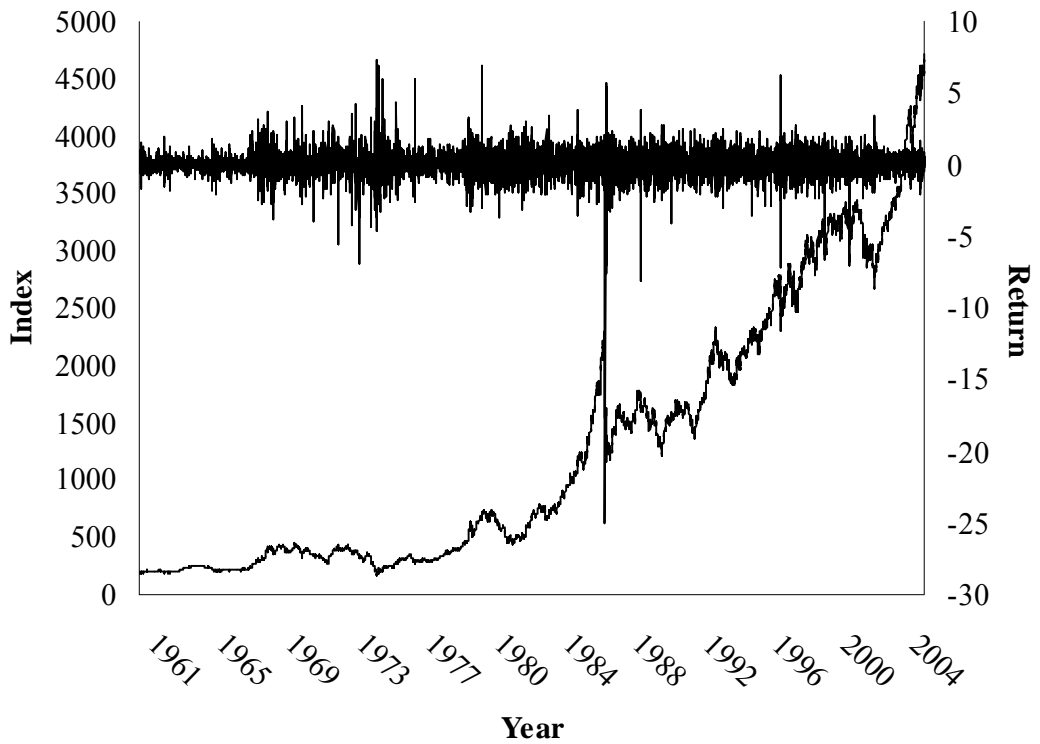

TABLE 1

DESCRIPTIVE ANALYSIS OF DAILY RETURNS

\begin{tabular}{lcccc}
\hline & $\begin{array}{c}\text { Melbourne Cup } \\
\text { Tuesdays }\end{array}$ & $\begin{array}{c}\text { November } \\
\text { Tuesdays }\end{array}$ & $\begin{array}{c}\text { Other } \\
\text { Tuesdays }\end{array}$ & $\begin{array}{c}\text { Other } \\
\text { days }\end{array}$ \\
\hline Number & 45 & 148 & 2114 & 9020 \\
Mean & 0.1916 & -0.2345 & -0.0352 & 0.0516 \\
Median & 0.1424 & -0.1186 & -0.0204 & 0.0554 \\
Maximum & 1.9091 & 4.3056 & 5.9383 & 7.2682 \\
Minimum & -0.8216 & -3.8913 & -24.9947 & -8.0963 \\
Standard. Dev. & 0.5574 & 0.9349 & 0.9455 & 0.8188 \\
Skewness & 1.3421 & 0.0716 & -8.8725 & -0.2729 \\
Kurtosis & 5.3902 & 7.7615 & 235.4750 & 12.1374 \\
Jarque-Bera & $2.42 \mathrm{E}+01$ & $1.40 \mathrm{E}+02$ & $4.79 \mathrm{E}+06$ & $3.15 \mathrm{E}+04$ \\
JB $p$-value & 0.0000 & 0.0000 & 0.0000 & 0.0000 \\
\hline N & N N N & &
\end{tabular}

Notes: Number-the number of observations in a given category; Melbourne Cup Tuesdays-the first Tuesday in November; November Tuesdays-other Tuesdays in November apart from Melbourne Cup Tuesday; Other Tuesdays-Tuesdays in months other than November; Other days-Monday, Wednesday, Thursday, and Friday trading days. Sample period Tuesday 3 January 1961 to Friday 30 December 2005. 
TABLE 2

TESTS OF MEAN DIFFERENCES

\begin{tabular}{|c|c|c|c|c|c|c|c|}
\hline \multicolumn{3}{|c|}{ Comparison groups } & \multirow[b]{2}{*}{ Mean } & \multicolumn{2}{|c|}{$\begin{array}{c}\text { Equality of } \\
\text { variances }\end{array}$} & \multicolumn{2}{|c|}{$\begin{array}{l}\text { Equality of } \\
\text { means }\end{array}$} \\
\hline First group & Mean & Second group & & $\begin{array}{c}F- \\
\text { statistic }\end{array}$ & $p$-value & $\begin{array}{c}t- \\
\text { statistic } \\
\end{array}$ & $p$-value \\
\hline Other days & 0.0516 & Other Tuesdays & -0.0352 & 0.6302 & 0.4273 & 4.2626 & 0.0000 \\
\hline Other days & 0.0516 & November Tuesdays & -0.2345 & 2.8398 & 0.0920 & 3.6994 & 0.0003 \\
\hline Other days & 0.0516 & $\begin{array}{c}\text { Melbourne Cup } \\
\text { Tuesdays }\end{array}$ & 0.1916 & 5.1298 & 0.0235 & -1.6759 & 0.1007 \\
\hline Other Tuesdays & -0.0352 & November Tuesdays & -0.2345 & 2.1477 & 0.1429 & 2.4777 & 0.0133 \\
\hline Other Tuesdays & -0.0352 & $\begin{array}{l}\text { Melbourne Cup } \\
\text { Tuesdays }\end{array}$ & 0.1916 & 2.6825 & 0.1016 & -1.6039 & 0.1089 \\
\hline $\begin{array}{c}\text { November } \\
\text { Tuesdays }\end{array}$ & -0.2345 & $\begin{array}{l}\text { Melbourne Cup } \\
\text { Tuesdays }\end{array}$ & 0.1916 & 7.1363 & 0.0082 & -3.7645 & 0.0003 \\
\hline
\end{tabular}

Notes: Melbourne Cup Tuesdays-first Tuesday in November each year; November Tuesdays-other Tuesdays in November apart from Melbourne Cup Tuesday; Other Tuesdays-Tuesdays in months other than November; Other days-Monday, Wednesday, Thursday, and Friday trading days. Levene's test for equality of variances determines whether the $t$-statistics and $p$-values for equality of means assume equal or unequal variances. Sample period Tuesday 3 January 1961 to Friday 30 December 2005.

\subsection{Parametric Tests of Mean Return Differences}

At first sight, there appears to be evidence of a 'Melbourne Cup effect' in the Australian stock market. In terms of returns, the mean Melbourne Cup return (0.1916) is higher than that of other days (0.0516) and is thereby associated with a one-day gain of $\$ 2,045$ million for Melbourne Cup Day 2005 alone, while the mean returns for other Tuesdays in November $(-0.2345)$ and Tuesdays in other months $(-0.0352)$ are negative. The $t$ tests in Table 2 comparing these mean returns indicate that these differences are mostly statistically significant. In terms of 'Melbourne Cup Tuesdays', the mean return is significantly more than 'November Tuesdays' at the 0.01 level. For 'Melbourne Cup Tuesdays' and other days and Tuesdays in months outside November, while the level of significance is not strictly lower than the 0.10 level, it is very close $(0.1007$ and 0.1089 , respectively). One suggestion is that the mean return for 'Melbourne Cup days' is nearly four times more than other days. The mean return on 'November Tuesdays' other than 'Melbourne Cup Tuesday' is negative, with returns for 'November Tuesdays' being nearly seven times lower than Tuesdays in other months of the year.

\subsection{Regression-based Analysis of the Melbourne Cup Effect}

The estimated coefficients and standard errors of the parameters detailed in (1) and (2) are presented in Table 3. The upper portion of Table 3 is where the dependent variable is specified as daily Monday to Friday price returns, while the lower portion details the results of regressions where only Tuesday returns comprise the dependent variable. The independent variables are dummy variables for 'Melbourne Cup day', 'other November Tuesdays' and 'all other Tuesdays'. Three different standard errors and $p$-values are calculated and presented in Table 3 for both regression models. These are standard errors and $p$-values obtained by: (i) ordinary least squares; (ii) those employing corrections for heteroskedasticity of unknown form (White); and (iii) those incorporating corrections for heteroskedasticity and autocorrelation of unknown form (Newey-West). 
TABLE 3

ESTIMATED COEFFICIENTS AND STANDARD ERRORS

\begin{tabular}{|c|c|c|c|c|c|c|c|c|}
\hline & \multirow[b]{2}{*}{ Independent } & \multirow[b]{2}{*}{ Coefficient } & \multicolumn{2}{|c|}{ Least squares } & \multicolumn{2}{|c|}{ White } & \multicolumn{2}{|c|}{ Newey-West } \\
\hline & & & $\begin{array}{c}\text { Standard } \\
\text { error }\end{array}$ & $p$-value & $\begin{array}{c}\text { Standard } \\
\text { error }\end{array}$ & $p$-value & $\begin{array}{c}\text { Standard } \\
\text { error }\end{array}$ & $p$-value \\
\hline \multirow{4}{*}{ 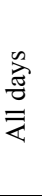 } & Constant & 0.0516 & 0.0089 & 0.0000 & 0.0086 & 0.0000 & 0.0101 & 0.0000 \\
\hline & Other Tuesdays & -0.0868 & 0.0204 & 0.0000 & 0.0223 & 0.0001 & 0.0223 & 0.0001 \\
\hline & November Tuesdays & -0.2861 & 0.0700 & 0.0000 & 0.0771 & 0.0002 & 0.0757 & 0.0002 \\
\hline & $\begin{array}{l}\text { Melbourne Cup } \\
\text { Tuesdays }\end{array}$ & 0.1400 & 0.1262 & 0.2674 & 0.0826 & 0.0902 & 0.0824 & 0.0895 \\
\hline \multirow{3}{*}{ 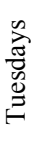 } & Constant & -0.0352 & 0.0204 & 0.0846 & 0.0206 & 0.0869 & 0.0217 & 0.1051 \\
\hline & November Tuesdays & -0.1992 & 0.0798 & 0.0126 & 0.0794 & 0.0121 & 0.0793 & 0.0120 \\
\hline & $\begin{array}{l}\text { Melbourne Cup } \\
\text { Tuesdays }\end{array}$ & 0.2269 & 0.1415 & 0.1089 & 0.0848 & 0.0075 & 0.0858 & 0.0083 \\
\hline
\end{tabular}

The dependent variable in the upper panel is the daily returns on All Ordinaries index Sample period Tuesday 3 January 1961 to Friday 30 December 2005. The dependent variable in the lower panel is the daily returns for Tuesdays only. 'Melbourne Cup Tuesdays'-first Tuesday in November; 'November Tuesdays'-Tuesdays in November apart from 'Melbourne Cup Tuesday'; 'Other Tuesdays'-Tuesdays in months other than November; 'Other days'-Monday, Wednesday, Thursday, and Friday trading days. Least squares-standard errors and $p$-values from ordinary least squares, White-standard errors and $p$-values employing corrections for heteroskedasticity of unknown form, Newey-West-standard errors and $p$-values employing corrections for heteroskedasticity and autocorrelation of unknown form.

Once again, the signs on the estimated coefficients appear to offer support for the posited Melbourne Cup effect. The signs on the Melbourne Cup are always positive, and the signs on other Tuesdays, both in November and other months are always negative, suggesting the simultaneous presence of 'Melbourne Cup' and 'day-of-theweek' market anomalies. That is, the 'Tuesday (day-of-the-week) effect' is associated with a lower mean return than other days and 'Tuesdays in November (other than Melbourne Cup Tuesday)' are lower than Tuesdays in other months of the year. However, the least squares estimates of the Melbourne Cup market returns are not significant at any conventional level.

Breusch-Godfrey Lagrange multiplier and White's heteroskedasticity tests are used to test for higher-order serial correlation and heteroskedasticity in the least-squares residuals, respectively. To start with, the null hypothesis of no serial correlation is rejected (statistic $=164.4310 ; p$-value $=0.0000$ ) and we may conclude the presence of higher-order serial correlation in the residuals. Then the null hypothesis of no heteroskedasticity in the least squares residuals fails to be rejected (statistic $=0.8237$; $p$ value $=0.4805)$. A Lagrange multiplier test for autoregressive conditional heteroskedasticity (ARCH) in the residuals is also conducted. While ARCH itself does not invalidate standard least-squares, ignoring these effects may result in a loss of efficiency. The null hypothesis of no ARCH also fails to be rejected (statistic $=0.8781$; $p$-value $=0.9474$ )

After corrections are made for heteroskedasticity (White) and heteroskedasticity and autocorrelation (Newey-West) of an unknown form, all of the parameters in Table 3 are significant at the 0.10 level or lower, irrespective of whether returns are specified as Mondays, Tuesdays, Wednesdays, Thursdays, and Fridays, or Tuesdays only. On average, Melbourne Cup returns are higher than other Tuesdays in the year, and higher 
than other days in the year. There is also evidence of a strong Tuesday 'day-of-the week effect' in the Australian market, with negative mean Tuesday returns throughout the year and even lower in November. This suggests that the posited 'Melbourne Cup effect' overrides both the (negative) 'day-of-the-week effect' (Tuesday) the and (negative) month-of-the-year effect (November) in the Australian market.

\section{Concluding Remarks}

The present study has employed parametric analysis to test for a 'Melbourne Cup effect' in the Australian stock market. A comparison of mean returns provides some empirical evidence to support the conjecture that 'Melbourne Cup Tuesday' is associated with a higher mean market return than either other Tuesdays or other days. After adjustments are made for heteroskedasticity and autocorrelation, similar results are obtained using a regression-based approach. This result is generally consistent with the market anomaly literature, which suggests that Tuesday returns are systematically lower than other days of the week. It provides also the first non-impressionistic evidence that the Melbourne Cup is associated with abnormally higher returns on the Australian stock exchange.

Of course, no effort has been made to identify the source of the 'Tuesday day-of-theeffect'. One argument is that it is linked to a time-delayed US market Monday effect, which in turn is derived from lags in payment and cheque clearing settlements, midweek time pressures on individuals, the tendency for financial advice to be given after Monday strategy-setting meetings, and to the larger percentage of purchases (sales) on Fridays (Mondays) at dealer ask (bid) prices. Neither is there any attempt to focus on the nature of the 'month-of-the-year effect', which has been attributed elsewhere to taxloss selling, portfolio rebalancing by investors and macroeconomic and company announcements.

There are likewise a number of issues concerning the 'Melbourne Cup effect' that have not been addressed and these indicate directions for future research. One possibility is to explore returns on the days following the Melbourne Cup to find evidence of a (negative) readjustment process. Another possibility is that the strength of the market effect may vary with race outcomes. For example, Narayan and Smyth (2004) posited that Melbourne Cup attendance varied with the appearance of 'legends of the turf', such as Carbine, Phar Lap, Rainlover, and Kingston Town; perhaps soon to be joined by the recently legendary Makybe Diva. Since it is conceivable that the market euphoria associated with the Melbourne Cup may also vary with 'popular horses that captured the imagination of fans' Narayan and Smyth $(2004,197)$ this possibility deserves further empirical attention.

Finally, and apart from the Melbourne Cup in Australia, it is not known whether other national race days have a similar effect on stock markets. For example, the Kentucky Derby (in the United States), the Grand National (in the United Kingdom) and the Japan Cup are also highly significant features on the global horse racing calendar, though clearly not with the same social impact as the Melbourne Cup has in Australia. Nonetheless, it would still be interesting to see if the effect documented in this study can be extended to a more global context.

\section{REFERENCES}

Agrawal, A. and D. L. Ikenberry (1994) "The Individual Investor and the Weekend Effect", Journal of Financial and Quantitative Analysis, 29, pp. 263-277. 
Agrawal, A. and K. Tandon (1994) "Anomalies of Illusions? Evidence from Stock Markets in Eighteen Countries", Journal of International Money and Finance, 13, pp. 83-106.

Arumugam, S. (1999) "Focus on High Stock Returns before Holidays: New Evidence from India", Journal of Financial Management and Analysis, 12, pp. 69-84.

Barberis, N. and R. Thaler (2003) "A Survey of Behavioural Finance" in G. M. Constantinides, M. Harris and R. Stulz (eds), Handbook of the Economics of Finance: Financial Markets and Asset Pricing (Amsterdam: Elsevier, North Holland), pp. 1053-1123.

Boyle, G and B. Walter (2003) "Reflected Glory and Failure: International Sporting Success and the Stock Market", Applied Financial Economics, 13, pp. 225-235

Brav, A., J. B. Heaton and A. Rosenberg (2004) "The Rational-Behavioural Debate in Financial Economics", Journal of Economic Methodology, 11, pp. 393-409.

Brockman, P. and D. Michayluk (1998) "The Persistent Holiday Effect: Additional Evidence", Applied Economics Letters, 5, pp. 205-209.

Cadsby, C.B. and M. Ratner (1992) "Turn-of-Month and Pre-Holiday Effects on Stock Returns: Some International Evidence", Journal of Banking and Finance, 16, pp. 497-509.

Chamberlain, T. W., C. S. Cheung and C. Y. Kwan (1991) "The Friday the Thirteenth Effect: Myth or Reality?", Quarterly Journal of Business and Economics, 30, pp. 111-117.

Chan, M. W. L., A. Khanthavit and T. Hugh (1996) "Seasonality and Cultural Influences on Four Asian Stock Markets", Asia Pacific Journal of Management, 13, pp. $1-24$.

Chang, E.C., J. M. Pinegar and R. Ravichandra (1993) "International Evidence on the Robustness of the Day-of-the-Week Effect", Journal of Financial and Quantitative Analysis, 28, pp. 497-513.

Chang, E. C., J. M. Pinegar and R. Ravichandran (1998) "U.S. Day-of-the-Week Effects and Asymmetric Responses to Macroeconomic News", Journal of Banking and Finance, 22, pp. 513-534.

Chong, R., R. Hudson, K. Keasey and K. Littler (2005) "Pre-Holiday Effects: International Evidence on the Decline and Reversal of a Stock Market Anomaly", Journal of International Money and Finance, 24, pp. 1226-1236.

Davidson, S. and R. W. Faff (1999) "Some Additional Australian Evidence on the Day of the Week Effect", Applied Economics Letters, 6, pp. 247-249.

Easton, S.A. and R.W. Faff (1994) "An Investigation of the Robustness of the Day-ofthe-Week Effect in Australia”, Applied Financial Economics, 4, pp. 99-110.

Edmans, A., D. Garćia and Ø. Norli (2007) "Sports Sentiment and Stock Returns", Journal of Finance, preprint at http://www.afajof.org/journal/forth_abstract.asp?ref=319.

Fama, E. F. (1998) "Market Efficiency, Long-Term Returns, and Behavioural Finance", Journal of Financial Economics, 49, pp. 283-306.

Finn, F. J., A. Lynch and S. Moore (1991) "Intra-week Regularities in Security Returns: Further Australian Evidence”, Australian Journal of Management, 16, pp. 129-144.

Global Financial Data (2006) http://www.globfindata.com.

Haugen, R.A. and P. Jorion (1996) "The January Effect: Still there after all these Years", Financial Analysts Journal, 52, pp. 27-31.

Jaffe, J. F. and R. Westerfield (1985) "The Weekend Effect in Common Stock Returns: The International Evidence”, Journal of Finance, 41, pp. 433-454. 
Kamara, A. (1997) "New Evidence on the Monday Seasonal in Stock Returns", Journal of Business, 70, pp. 63-84.

Kim, C. W. and J. Park (1994) "Holiday Effects and Stock Returns: Further Evidence", Journal of Financial and Quantitative Analysis, 29, pp. 145-157.

Lin, C. T. and L. K. Lim (2001) "On the Disappearance of the Tuesday Effect in Australia", School of Finance and Business Economics Working Paper Series, Working Paper 01.12, Edith Cowan University.

McGuinness, P. B. (2005) "A Re-examination of the Holiday Effect in Stock Returns: The Case of Hong Kong", Applied Financial Economics, 15, pp. 1107-1123.

Narayan, P. K. and R. Smyth (2003) "Attendance and Pricing at Sporting Events: Empirical Results from Granger Causality Tests for the Melbourne Cup", Applied Economics, 35, pp. 1649-1658.

Narayan, P. K. and R. Smyth (2004) "The Race that Stops a Nation: The Demand for the Melbourne Cup", The Economic Record, 80, pp. 193-207.

Rosenberg, M. (2004) "The Monthly Effect in Stock Returns and Conditional Heteroskedasticity", American Economist, 48, pp. 67-73.

Shiller, R.J. (2003) "From Efficient Markets Theory to Behavioural Finance", Journal of Economic Perspectives, 17, pp. 83-104.

Tonchev, D. and T. H. Kim (2004) "Calendar Effects in Eastern European Financial Markets: Evidence from the Czech Republic, Slovakia and Slovenia", Applied Financial Economics, 14, pp. 1035-1043.

van der Sar, N. L. (2004) "Behavioural Finance: How Matters Stand", Journal of Economic Psychology, 25, pp. 425-44.

Vergin, R. C. and J. McGinnis (1999) "Revisiting the Holiday Effect: Is it on Holiday?", Applied Financial Economics, 9, pp. 477-482.

Wang, K., Y. Li and J. Erickson (1997) "A New Look at the Monday Effect", Journal of Finance, 52, pp. 2171-2186.

Zainudin, A. and J.A. Coutts (1997) "Security price anomalies in the London International Stock Exchange: A 60 year perspective", Applied Financial Economics, 7, pp. 455-464. 